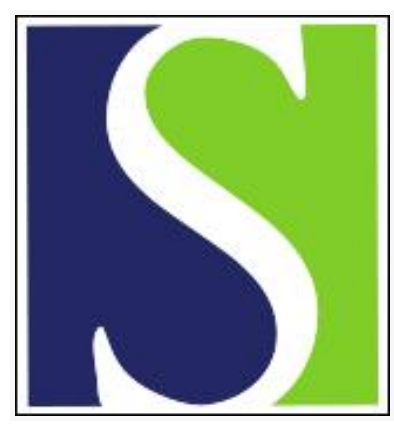

Scand J Work Environ Health 1978;4(4):330-335

https://doi.org/10.5271/sjweh.2692

Issue date: Dec 1978

Vasospastic symptoms caused by asymmetrical vibration exposure of the upper extremities to a pneumatic hammer. by Färkkilä M, Starck J, Hyvärinen J, Kurppa K

Key terms: asymmetrical vibration exposure; pneumatic hammer; upper extremity; vasospastic symptom; vibration; vibration exposure; vibration spectra

This article in PubMed: www.ncbi.nlm.nih.gov/pubmed/734394

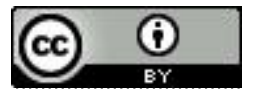




\title{
Vasospastic symptoms caused by asymmetrical vibration exposure of the upper extremities to a pneumatic hammer
}

\author{
by MARKUS FÄRKKILÄ, M.D.1, JUKKA STARCK, M.Sc.,2 JUHANI \\ HYVÄRINEN, M.D., ${ }^{1}$ and KARI KURPPA, M.D. ${ }^{2}$
}

\begin{abstract}
FÄRKKILÄ, M., STARCK, J., HYVÄRINEN, J. and KURPPA, K. Vasospastic symptoms caused by asymmetrical vibration exposure of the upper extremities to a pneumatic hammer. Scand. j. work environ. \& health 4 (1978) 330-335. The vibration spectra of a pneumatic hammer, Atlas Copco BHV-type, was analyzed from the wrists of workers and from the tool during use. Sixteen men who were exposed to the vibration of the tool were examined for hand-arm symptoms associated with vibration. The hypothesis was that the left hand, holding the chisel head, would be more affected than the right hand, holding the barrel of the hammer. The asymmetry in symptoms between the left and right hands was examined on the basis of history, a clinical examination, and a cold provocation test. The vibration from the chisel head of the tool was of a higher frequency than that from the hammer. The vibration acceleration was 1,000 -fold greater in the chisel head than in the barrel of the hammer, and it was higher in the frequency range from 100 to $1,000 \mathrm{~Hz}$. Also the left hand was more affected both on the basis of the workers' history and the cold provocation test. This asymmetrical exposure is very rare today, and the differences in the severity of symptoms between the left and right hands are mild, although the history of these workers indicate that the symptoms were grossly asymmetrical 10 to 20 years ago when asymmetrical exposure was common.
\end{abstract}

Key words: asymmetrical vibration exposure, pneumatic hammer, vasospastic symptoms, vibration spectra.

Numerous hypotheses have been proposed for the physiologial mechanism of the genesis of vibration disease, but there has not yet been any generally accepted explanation for vasospastic symptoms $(2,11)$. The variety of hygienic regulation in different countries shows that the correct

1 Department of Physiology, University of Helsinki, Helsinki, Finland.

2 Institute of Occupational Health, Helsinki, Finland.

Reprint requests to: Dr. Markus Färkkilä, Department of Physiology, University of Helsinki, Siltavuorenpenger 20 a, SF-00170 Helsinki 17, Finland. theory is still to be determined (9). In 1973 Hyvärinen et al. (3) suggested that vasospastic symptoms were due to a sympathetic vasoconstrictor reflex triggered by vibration. Accordingly, the Pacinian corpuscles would act as receptors in the afferent part of the reflex arch. The vibration would cause activation hypertrophy of the vasoconstrictor smooth muscle, and the obliterated digital arteries would be more prone to collapse because of vibration, noise and cold (3). The Pacinian corpuscle follows the vibration frequency strictly up to frequencies of about $500 \mathrm{~Hz}$. On the basis of this observation the vaso- 
spastic symptoms should be more common in the hand receiving vibration of a higher frequency.

Symptoms of white fingers are reported to be asymmetrical in association with some tools $(5,7,10)$. This asymmetrical distribution has been explained as being due to different grips on the tools and to different compression forces in the fingers during work (5). Workers in the stone industry who use the Atlas Copco BHV type of pneumatic hammer are exposed asymmetrically to vibration. The exposure time is the same for both hands, but the hand holding the chisel head is exposed to higher frequencies and acceleration levels than the hand holding the barrel of the hammer. In the present study we investigated the distribution of vasospastic symptoms between the hands of each worker and the dependence of the symptoms on vibration frequency and acceleration level.

\section{METHODS AND MATERIAL}

The quality and quantity of the vibration of the pneumatic hammers used by stoneworkers were measured and analyzed. The points at which the vibration transducers were fixed were the chisel head and barrel of the hammer and the wrists of the worker. The main axis of the transducers was in the direction of the strike of the hammer in the tool and in the direction of the lower arm in the wrist. An Atlas Copco type BHV-22 hammer was used for the measurements. It had the following technical characteristics: diameter of piston $22 \mathrm{~mm}$, strike length $30 \mathrm{~mm}$, strike frequency 5,000 per minute and 83 per second, weight $1.4 \mathrm{~kg}$.

Fig. 1 shows the manner in which the vibration transducers were fixed to the chisel head and barrel of the hammer and to the worker's wrists. First a piece of metal was welded to the chisel head, and the transducer was fastened to it with a screw. During the measurements made from the body of the hammer, the transducer was fastened with a screw to an angle bar which was fixed to the round bar- rel of the hammer. For the measurement of wrist vibration, the transducer was simply fastened to a plastic plate which was adjusted to fit against the styloid process of the wrist and held there a with tightener and a plastic support. A rigid fixation was used to avoid the response of cutaneous, subcutaneous, and connective tissue around the bone. All screw joints were reinforced with wax and tape and insulated with foam rubber.

The following measuring and analyzing instruments were used: vibration transducers (accelerometer B \& K 4344 and 4371), a measuring amplifier (charge amplifier B \& K 2635), a display unit (B \& K 5743), an FM tape recorder (B \&K 7003), a 1/3 octave sealtime analyzer (B \& K 3347), and a level recorder ( $B$ \& K 2305). The upper limit of the amplifier was restricted to $1,000 \mathrm{~Hz}$. The vibration sample for laboratory analysis was recorded during normal work,
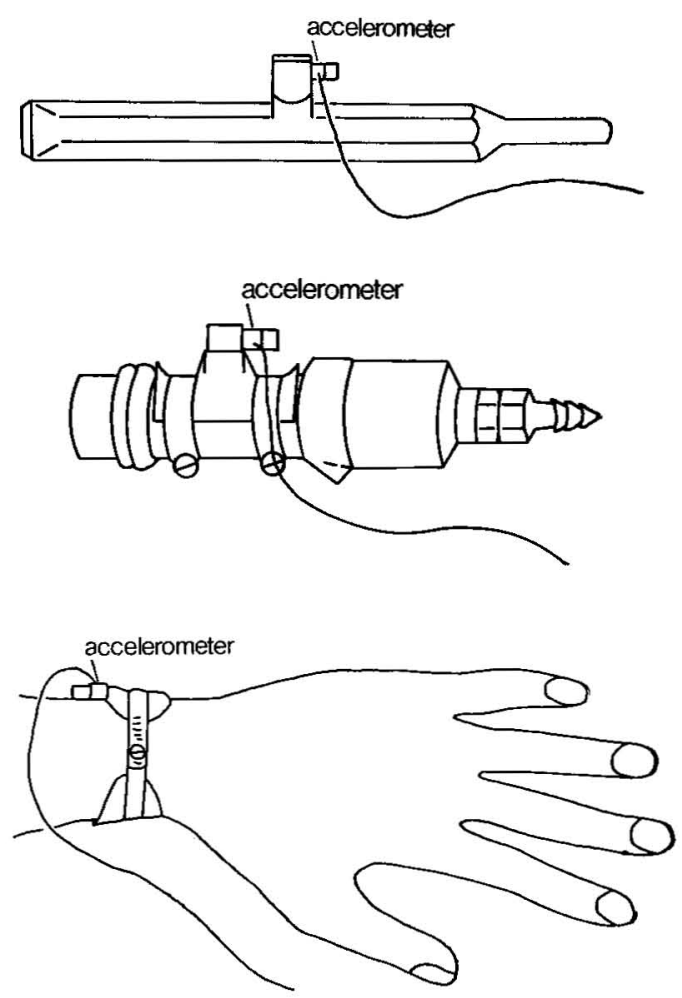

Fig. 1. Mounting of an accelerometer: (a) the chisel head of the hammer, (b) the barrel of the hammer, and (c) the wrist. 
Table 1. Maximum components of the acceleration spectra from the tool and the wrists.

Vibration acceleration $\left(\mathrm{m} / \mathrm{s}^{2}\right)$ in $1 / 3$ octave band $80 \mathrm{~Hz}$

\begin{tabular}{lcc}
\cline { 2 - 3 } & $\begin{array}{c}\text { Chisel head/ } \\
\text { left hand }\end{array}$ & $\begin{array}{c}\text { Barrel/ } \\
\text { right hand }\end{array}$ \\
\hline Tool & 27,000 & 31 \\
Wrist & 17 & 4 \\
\hline
\end{tabular}

and the length of the sample was $5 \mathrm{~min}$. In the laboratory, vibration acceleration was analyzed in $1 / 3$ octave bands in the frequency range of $12.5-1,000 \mathrm{~Hz}$. All the instruments were calibrated by a constant vibration source (B \& K 4291) before and after the measurements.

We examined 16 workers who used pneumatic hammers professionally. The subjects were selected on the basis of (a) a list of exposed workers in the stone industry (1) and (b) the list of stonework firms in the 1975 Finnish telephone directory. The subjects had been exposed to the Atlas Copco BHV 16-30 hammer, although currently this type of exposure is much less than earlier. The workers also used other vibrating tools.

The mean age of the subjects was $53.6 \pm$ 11.6 (SD) years, and their mean exposure time to pneumatic hammer vibration was $25,600 \mathrm{~h}$, the range being from 2,000 to $50,000 \mathrm{~h}$. The grip on the hammer during use was similar for all the subjects independently of the dominant hand.

The subjects came from different parts of Finland to the Institute of Occupational
Health in Helsinki for the study. At the Institute, a general clinical examination, a radiological examination of the hands, and laboratory tests (electrocardiogram, sedimentation rate, hemoglobin, urinary proteins and urinary glucose) were made, and a complete history of symptoms was recorded to rule out other possible causes than vibration for the occurrence of Raynaud's phenomenon. A cold provocation test was also carried out (7) in which the number of affected phalanges was counted and the recovery time was measured. With a temperature recorder (type $\mathrm{Z} 8$, made by Ellab Instruments), the skin temperature was measured electrically from the tip of the third finger of both hands just before and after the cold provocation test.

The asymmetry between hand symptoms was determined according to the following parameters: the occurrence of white fingers in either hand, initiation of symptoms, duration of the symptoms in years, recovery time after an attack, frequency of attacks, type of weather conditions which provoke attacks, number of phalanges affected, subjective weakness of grip force, occurrence of numbness in hands, and severity of numbness in hands.

\section{RESULTS}

In all the vibration spectra the strike frequency of $83 \mathrm{~Hz}$ occurred; this frequency corresponds to the maximum

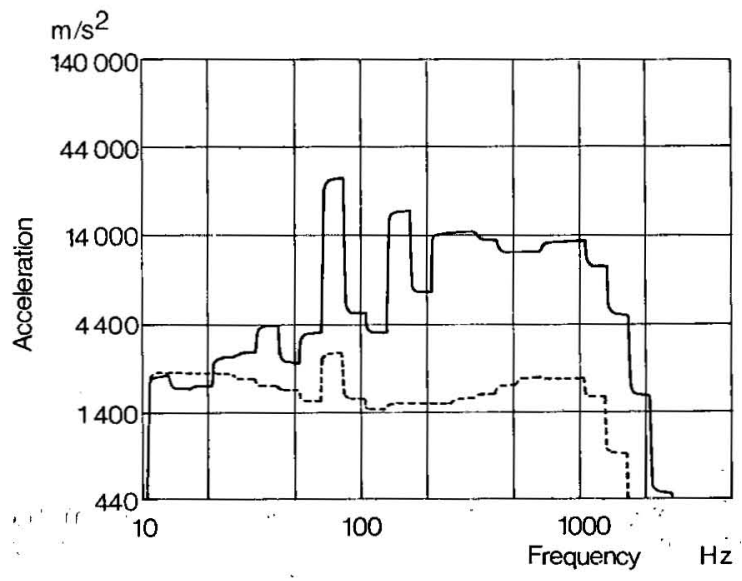

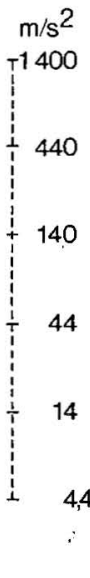

Fig. 2. Vibration acceleration in $1 / 3$ octave bands. [- the chisel head in the direction of the strike (left scale); -.. the hammer barrel in the direction of the strike (right scale)] 
values of acceleration spectra in the $80 \mathrm{~Hz}$ $1 / 3$ octave band. The left hand was in touch with the chisel head, and the right with the barrel of the tool. The differences measured between the maximum components of vibration acceleration in the chisel head or barrel of the tool and the operator's wrists are presented in table 1.

The curves in figs. 2 and 3 represent the mean values of the sample. The acceleration in the chisel head was nearly 1,000 times higher than that in the barrel of the hammer. The difference measured in the operator's wrists was clearly lower. The vibration in the wrist of the left hand holding the chisel head was four times higher than that in the right hand. Moreover the frequencies over $100 \mathrm{~Hz}$ were strongly damped in the wrist. The damping of high frequencies in the hand has previously been reported by Pyykkö et. al. 1976 (8).

Of the 16 examined subjects, 14 had a history of white fingers. The symptoms had started in the left hand of nine subjects and in the right hand of three subjects, while two remembered that white fingers had appeared at the same time in both hands. In six cases the symptoms were bilateral; in only one of the six had the symptoms started in the right hand. In three of the six cases, white fingers had started four or five years earlier in the left hand. In two cases the symptoms began to appear the same year. The vasospastic symptoms were not different among those who had worked in warmer indoor conditions in comparison to those who worked outdoors.

Eleven of the 13 subjects who took part in the cold provocation test had a history of white fingers, and for seven of these subjects $(64 \%)$ the results were positive. For six the left hand was more severely affected, and for one the right hand was more affected. The results of the cold provocation test are shown in fig. 4.

The mean skin temperature was reduced during the cold provocation test by $12.6^{\circ} \mathrm{C}$ in the left hand and $11.6^{\circ} \mathrm{C}$ in the right. There were no significant differences in skin temperature between subjects with or without white fingers in the cold provo-

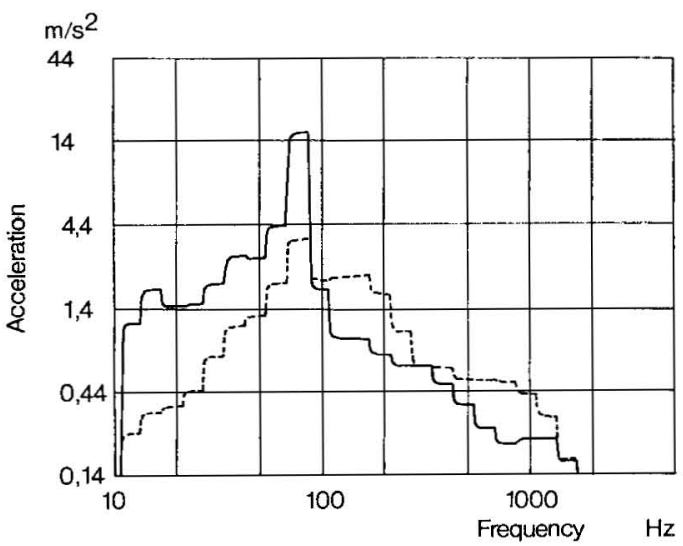

Fig. 3. Vibration acceleration caused by the tool in $1 / 3$ octave bands. ( $\longrightarrow$ the wrist of the left hand; - - the wrist of the right hand)
Fig. 4. Means and standard deviations of the time taken to recover from an attack of traumatic vasospastic disease and the number of affected phalanges in the left and right hands in the cold provocation test.

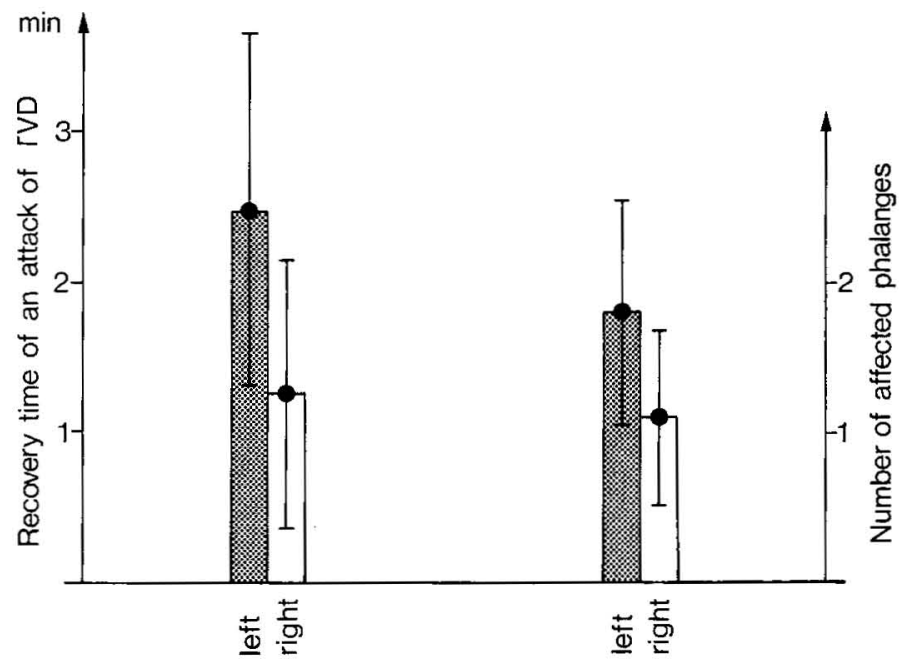


cation test, and the subjects' blood pressure did not change.

In the radiographic examination symmetrical arthrotic changes were noted in the metacarpal and carpal bones, but the changes did not correlate with white fingers of vibration exposure.

For the statistical analysis the following five parameters were chosen: a history of white fingers in the left or right hand, reported recovery time after an attack of white fingers, reported number of affected phalanges, recovery time after an attack of white fingers in the cold provocation test, and number of phalanges affected in the cold provocation test. The left hand was more affected for all the parameters, but the difference was not statistically significant (Student's t-test for paired data, $\mathrm{t}=1,03, \mathrm{~N}=15$ ).

\section{DISCUSSION}

During work with a pneumatic hammer the right hand holds the hammer tight and presses it towards the stone. The left hand touches the chisel head lightly. The grip force affects the transmission of vibration to the hand (8). The vibration of the hammer was eight times stronger than the accepted limit for $8 \mathrm{~h}$ of daily exposure $(4,6)$. Besides it was transmitted to the hands to such an extent that it was even possible for the disease to develop in the right hand. The vibration of the chisel head was 8,000 times stronger when compared to the same limit. The vibration spectra of the chisel head and of the hammer is seen in fig. 2. Not all of the vibration was transmitted to the left hand, as is seen in fig. 3. The vibration acceleration was only four times higher in the left wrist than in the right. Much vibration was damped in the hands, especially the frequencies from 100 to $1,000 \mathrm{~Hz}$. The acceleration was higher in the vibration spectra of the left wrist than in that of the right, but there was no difference in the high frequencies measured from the wrist, as seen in fig. 3 .

Between the vibration frequencies of $160-1,000 \mathrm{~Hz}$ the left hand is exposed to an acceleration of $14,000 \mathrm{~m} / \mathrm{s}^{2}$, and the right hand to only that of about $20 \mathrm{~m} / \mathrm{s}^{2}$. The vibration spectra measured from the wrists showed that the high frequencies were damped in the palm and fingers so that the respective accelerations measured from the wrists were between $3.0 \mathrm{~ms}^{-2}$ and $0.3 \mathrm{~ms}^{-2}$.

In the course of the examination we discovered that it was difficult to find workers exposed only to pneumatic hammer vibration. In large stone quarries methods have improved so much that the use of pneumatic hammers of this type has diminished.

Currently the use of the Atlas Copco BHV model is limited to special stages in work at small shops, and hardly anyone is greatly exposed. Therefore the number of subjects is small. The use of this type of pneumatic hammer was more widespread in the 1940 s and 1950 s, but since then it has diminished gradually. In fact so much time had passed that the subjects had difficulty remembering the strict differences between their hands, and this fact may have diminished the asymmetry in the history of symptoms. Fourteen different parameters were examined for differences between the hands, and they all showed that the left hand was more affected, although the difference was not statistically significant. The oldest subjects remembered that 20 years ago their left hand was often white during cold mornings, and it was then considered to be a normal phenomenon in work with pneumatic hammers. With changing work methods asymmetrical vibration exposure may be disappearing altogether, and we may now face the last moment to document its effects. Since exposure to vibration is diminishing, the severity of symptoms of traumatic vasospastic disease is decreasing, and the decrease in asymmetrical exposure is resulting in more symmetrical symptoms.

St. Clair Renard (10) reported an asymmetrical disease of the same kind among miners in Sweden. These workers had more severe disease in the hand which received vibration of a higher frequency. In the vibration spectra in fig. 2 the content of higher frequencies is remarkably larger in the hand holding the chisel head (left hand). Our results suggest that the energy 
is absorbed in the fingers and palm of the left hand to a larger extent than in the right hand. The differences in vibration acceleration correlate with the right-left differences in symptoms, a finding also supported by the clearly left-sided results of the cold provocation test.

\section{REFERENCES}

1. AHLMAN, K., BACKMAN, A.-L., HANNUNKARI, I., JÄRVINEN, E., KOPONEN, M., KOSKELA, R.-S., PARTANEN, T., SEPPÄLÄINEN, A.-M. and STARCK, J. Kivityön terveysriskit. (Työterveyslaitoksen tutkimuksia no. 102). Institute of Occupational Health, Helsinki $1975.73 \mathrm{p}$.

2. BIRNSTINGL, M. The Raynaud syndrome. Postgrad. med. j. 47 (1971) 297-310.

3. HYVÄRINEN, J., PYYKKÖ, I. and SUNDBERG, S. Vibration frequencies and amplitudes in the aetiology of traumatic vasospastic disease. Lancet 1 (1973) 791-794.

4. INTERNATIONAL OFFICE FOR STANDARDIZATION (ISO/TC 108/SC4 (Secr. 6)

14). Draft proposal for guide for the mea- surement and the evaluation of human exposure to vibration transmitted to the hand. Geneva 1975, pp. 1-17.

5. KAKOSY, T. and SZEPESI, L. Effects of vibration exposure on the localization of Raynaud's phenomenon in chain saw operators. Work environ. health 10 (1973) 134139.

6. NATIONAL BOARD OF LABOR PROTECTION. Koneet, välineet ja muut tekniset laitteet (yleiset koneohjeet) (Turvallisuusmääräykset no. 1). Tampere 1976, pp. 44-45.

7. PYYKKO, I. A physiological study of the vasosconstrictor reflex in traumatic vasospastic disease. Work environ. health 11 (1974) $170-186$.

8. PYYKKO, I., FÄRKKILA, M., TOIVANEN, J., KORHONEN, O. and HYVÄRINEN, J. Transmission of vibration in the hand-arm system with special reference to changes in compression force and acceleration. Scand. j. work environ. \& health 2 (1976) $87-95$.

9. REYNOLDS, D. and JOKEL, C. Hand-arm vibration - An Engineering approach. $A m$. ind. hyg. j. 35 (1974) 613-622.

10. ST. CLAIR RENARD, K. G. Kärlkramp vid borrningsarbetare. Medd. sven. gruvfören. 7 (1963) $1-55$.

11. TAYLOR, W. The vibration syndrome: Introduction. In: W. TAYLOR (ed.), The vibration syndrome. Academic Press, London 1974, pp. 1-12.

Received for publication: 5 June 1978 